\title{
The effect of cold tetracaine on the severity of burning sensation upon instillation
}

This article was published in the following Dove Press journal:

Clinical Ophthalmology

\author{
Wiwan Sansanayudh' \\ Thitima Phansucharitthai' \\ Nakarin Sansanayudh ${ }^{2}$ \\ 'Ophthalmology Department, \\ Phramongkutklao Hospital, Bangkok, \\ Thailand; ${ }^{2}$ Department of Internal \\ Medicine, Phramongkutklao Hospital, \\ Bangkok, Thailand
}

Purpose: Tetracaine is one of the most common eye drops that are used for analgesia in clinical practice. However, it causes ocular burning sensation when instilled. This study aimed to compare the effects of the cold and room temperature tetracaine on burning sensation.

Patients and methods: We conducted a prospective, double-blinded, randomized controlled trial at the ophthalmology outpatient clinic, Phramongkutklao Hospital during January 2016February 2017. In this study, 424 consecutive patients (those with a history of keratopathy or neuropathy were excluded) who received dilated fundus examination were randomized to receive cold tetracaine $\left(4^{\circ} \mathrm{C}\right)$ in one eye and room temperature tetracaine $\left(22.5^{\circ} \mathrm{C}\right)$ in the other eye. Each patient was asked to answer the questionnaire on the severity of burning sensation using $100 \mathrm{~mm}$ visual analog scale.

Results: Patients reported less burning sensation on the eye that received cold tetracaine (visual analog scale $20.50 \pm 18.8$ vs $22.70 \pm 20 \mathrm{~mm} ; P=0.025$ ). In the subgroup analysis, young patients ( $\leq 40$ years old), female subjects, patients who received tetracaine for the first-time and those who had no previous ocular surgery reported more benefit from cold tetracaine. The subgroup of patients who had normal corneal sensation, identified by using a Cochet-Bonnet esthesiometer, also showed greater benefit from cold tetracaine compared to those with impaired corneal sensation.

Conclusion: Cold tetracaine caused less burning sensation than room temperature solution. Its benefit was greater in the subgroup of patients who reported more severe burning sensation. We recommend using cold tetracaine in routine practice, especially in those who are anticipated to have this common side effect.

Keywords: ocular pain, anesthesia, temperature, corneal sensation, burning sensation

\section{Introduction}

Topical ophthalmic anesthesia is a part and parcel of ophthalmic examinations and procedures these days. It is widely used because of its rapid onset, easy application, and the low risk of side effects. There are many different types of topical anesthetic agents. Tetracaine is one of the most common topical anesthetics used in general practice due to its efficacy and wide availability.

While instillation of tetracaine is easy and lasts long enough for most ophthalmic examinations and procedures, it can often cause burning sensation and ocular pain. ${ }^{1-4}$ These adverse effects can be very unpleasant to the patients and they are the main limitations of tetracaine use in clinical practice. Various studies have tried to look into ways of attenuating these adverse effects. ${ }^{1-3,5-10}$ Adjusting the temperature of the solution may be a viable option for this.

There have been few studies regarding the effect of temperature of tetracaine solution on burning sensation. ${ }^{1,11,12}$ The results of these studies suggested that lowering the temperature of tetracaine eye drop may alleviate ocular pain on instillation. ${ }^{11,12}$
Correspondence: Nakarin Sansanayudh 315 Ratchawithi Rd, Phayathai, Rachathewi, Bangkok 10400, Thailand Tel +6623543827

Fax +66 26444755

Email dr_nakarin@hotmail.com
Clinical Ophthalmology 2018:12 2377-2382

(c) (i) (5) 2018 Sansanayudh et al. This work is published and licensed by Dove Medical Press Limited. The full terms of this license are available at https://www.dovepress.com/terms.php (c) ${ }_{\mathrm{BY}} \mathrm{NC}$ and incorporate the Creative Commons Attribution - Non Commercial (unported, v3.0) License (http://(reativecommons.org/licenses/by-nc/3.0/). By accessing the work you hereby accept the Terms. Non-commercial uses of the work are permitted without any further permission from Dove Medical Press Limited, provided the work is properly attributed. For permission for commercial use of this work, please see paragraphs 4.2 and 5 of our Terms (https://www.dovepress.com/terms.php). 
However, the sample size of these studies was relatively small and was not statistically calculated. In addition, nearly all these studies were performed in healthy volunteers ${ }^{12,13}$ and only one study was conducted in patients undergoing phacoemulsification. ${ }^{11}$ As such, the outcome of these findings may not be generalizable to the patients undergoing ophthalmic examination in ophthalmology clinic.

In view of this, we conducted a prospective, doubleblinded, randomized controlled trial comparing the effect of cold vs room temperature topical tetracaine on the severity of burning sensation in all comers of the ophthalmic outpatient clinic.

\section{Patients and methods}

This was a prospective, double-blinded, randomized controlled clinical trial conducted during January 2016February 2017.

Consecutive patients attending the ophthalmic outpatient department at Phramongkutklao Hospital, who met the following criteria, were included in the study: age 20 years and above, imperative dilated fundus examination in both eyes and well communicative. The patients who had history of keratopathy or neuropathy (evaluated by using the CochetBonnet esthesiometer [C-BA] $<2 \mathrm{~cm}$ ) were excluded. Written informed consent was obtained in all patients. The study was approved by the institutional review board of the Royal Thai Army Medical Department.

We prepared two groups of $0.5 \%$ tetracaine hydrochloride ophthalmic solution (Alcon Laboratories, Inc., Fort Worth, TX, USA). The first group was kept in the refrigerator $\left(4^{\circ} \mathrm{C}\right)$ at least 24 hours before using, whereas the other group was stored at room temperature (mean $22.5^{\circ} \mathrm{C}$, range $22^{\circ} \mathrm{C}-23^{\circ} \mathrm{C}$ ).

Demographic data, ocular history (ocular disease, history of previous ophthalmic surgery, history of contact lenses wear and frequency of the previous tetracaine eye drop instillation) and findings of ocular examination (visual acuity, corneal sensation using the C-BA, Schirmer I test) were recorded.

The subjects were randomized to receive cold or room temperature tetracaine in one eye, followed by the other solution in the other eye using block of 4 randomization. They were not informed whether the solution was cold or at room-temperature. We also wanted to study the impact of instillation sequence on the severity of side effects. Therefore, the sequence of instillation was also randomized. Half of the subjects were randomized to receive instillation of cold tetracaine first followed by the room temperature solution in the other eye, whereas the other half received instillation of room temperature tetracaine first followed by cold solution.
Each adverse symptom was thoroughly evaluated using a constructed questionnaire. The severity of each symptom was assessed using a $100 \mathrm{~mm}$ visual analog scale (VAS) by one researcher who was blinded to the treatment allocation.

\section{Sample size}

Assuming an SD of the VAS of 24.29 and setting a \% error of 5 , the minimum sample size was set at 342 with a 0.90 power to detect a difference of six between the groups.

\section{Statistical analyses}

Statistical analyses were performed using SPSS software version 23.0 (IBM Corporation, Armonk, NY, USA). Continuous variables were analyzed using the unpaired Student's $t$-test or paired $t$-test as appropriate. The chi-squared test or Fisher's exact test was used to evaluate categorical data as appropriate. $P$-values $<0.05$ were considered statistically significant.

\section{Results}

A total of 424 patients were enrolled in the study. Mean \pm SD age was $59.84 \pm 15.80$ years. The numbers of female and male were almost equal. Almost $70 \%$ had no history of dry eye disease. The demographic data are shown in Table 1. We performed the analysis on the sequence of instillation and we did not find the order effect.

Patients who received cold tetracaine reported significantly less burning sensation than with room temperature tetracaine $(20.50 \pm 18.8$ and $22.70 \pm 20 \mathrm{~mm}$, respectively; $P$-value 0.025 ), as shown in Figure 1 . However, other

Table I Demographic characteristics of the study population

\begin{tabular}{|c|c|}
\hline & Total number of subjects $(\mathrm{N}=424)$ \\
\hline \multicolumn{2}{|l|}{ Age, mean $\pm S D$} \\
\hline \multicolumn{2}{|l|}{ Gender, n (\%) } \\
\hline Female & $219(51.7)$ \\
\hline Male & $205(48.3)$ \\
\hline \multicolumn{2}{|l|}{ History of surgery, n (\%) } \\
\hline No & $280(66)$ \\
\hline Yes & $144(34)$ \\
\hline Hypertension, n (\%) & $222(52.4)$ \\
\hline Diabetic mellitus, n (\%) & $199(46.9)$ \\
\hline \multicolumn{2}{|l|}{ Dry eye disease, $\mathrm{n}(\%)$} \\
\hline No & $287(67.7)$ \\
\hline Yes & $137(32.3)$ \\
\hline \multicolumn{2}{|l|}{ Glaucoma, n (\%) } \\
\hline No & $375(88.4)$ \\
\hline Yes & $49(11.6)$ \\
\hline
\end{tabular}




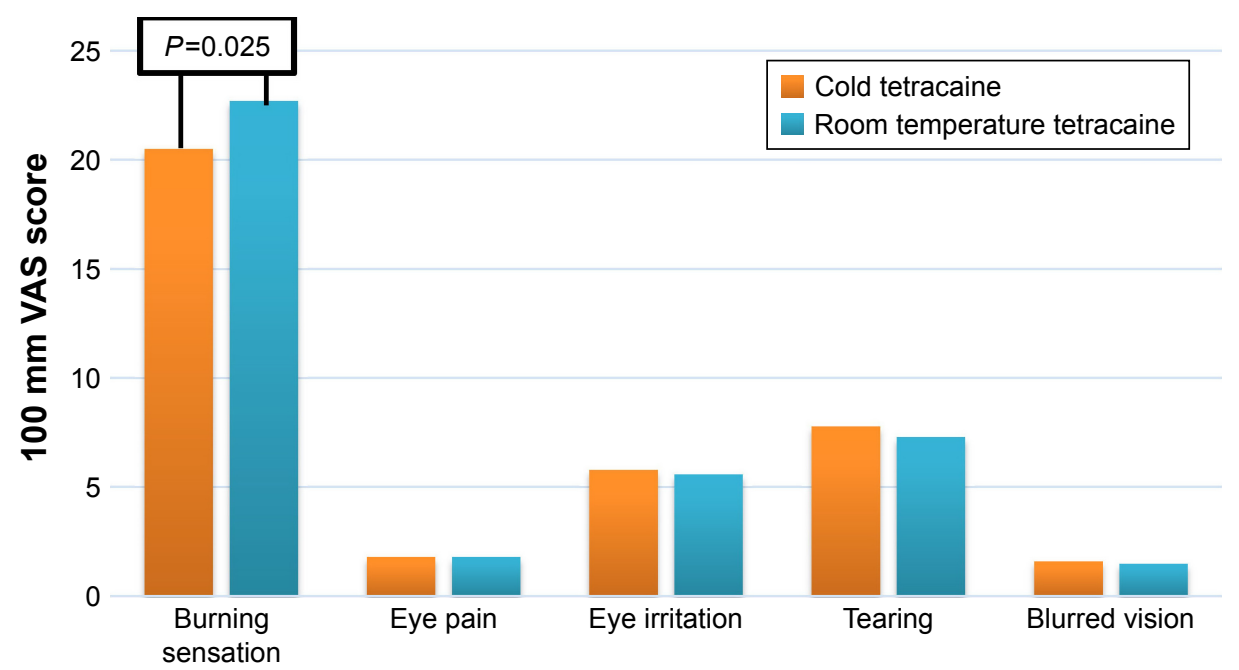

Side effects

Figure I Comparison of mean VAS scores of the symptoms between instillation of cold tetracaine vs room temperature tetracaine.

Note: The VAS burning sensation score of cold tetracaine was significantly lower than that of room temperature solution ( $P$-value 0.025$)$.

Abbreviation: VAS, visual analog scale.

symptoms including eye pain, eye irritation, tearing and blurred vision were not statistically different. No complications were observed throughout the study.

We performed further analysis to identify the subgroups of patients who reported higher VAS score of burning sensation and the subgroups that showed more benefit from using cold tetracaine (Tables 2 and 3).

Patients who had no previous history of ocular surgery had more VAS burning sensation score $(22.7 \pm 20.0$ vs $19.1 \pm 18.0 \mathrm{~mm} ; P=0.008)$. Patients who had preserved corneal sensation $(\mathrm{C}-\mathrm{BA}>3 \mathrm{~cm})$ also reported more severe burning sensation compared to patients who had impaired corneal sensation $(25.8 \pm 20.2$ vs $21.4 \pm 19.1 \mathrm{~mm} ; P=0.011)$. Patients who used tetracaine for the first-time in the previous year (first-time users) reported more burning sensation compared to patients who had experience of using tetracaine at least once in the previous year $(24.8 \pm 11.3$ vs $19.4 \pm 18.1 \mathrm{~mm}$; $P<0.001)$. There was a trend for more severe VAS score in female and younger patients, although the difference did not reach statistical significance as shown in Table 2 .

Female and younger patients reported more beneficial effect from cold tetracaine $(20.8 \pm 19.6$ vs $24.5 \pm 20.5 \mathrm{~mm}$, $P=0.007$ and $23.5 \pm 19.3$ vs $35.7 \pm 24.3 \mathrm{~mm}, P<0.001$, respectively). Patients who had no history of previous ocular surgery, the subgroup that was expected to have intact corneal sensation, had significantly less burning sensation score with cold tetracaine. Subjects who used tetracaine for the first-time in the previous year (first-time user) also had more benefit from cold tetracaine $(21.9 \pm 20.7$ vs $27.9 \pm 21.7$; $P=0.001)$. Participants who had preserved corneal sensation
Table 2 Subgroups of patients and VAS score of burning sensation at room temperature (independent sample $t$-test)

\begin{tabular}{|c|c|c|c|}
\hline & $\mathbf{n}$ & $\begin{array}{l}\text { VAS score of } \\
\text { burning } \\
\text { sensation } \\
\text { (mean } \pm \text { SD) }\end{array}$ & $P$-value \\
\hline \multicolumn{4}{|l|}{ Age, years } \\
\hline$\leq 40$ & 49 & $23.4 \pm 19.3$ & 0.241 \\
\hline$>40$ & 375 & $20.1 \pm 18.7$ & \\
\hline \multicolumn{4}{|l|}{ Gender } \\
\hline Male & 205 & $20.5 \pm 18.7$ & 0.111 \\
\hline Female & 219 & $22.6 \pm 20.1$ & \\
\hline \multicolumn{4}{|l|}{ Corneal sensation } \\
\hline C-BA $>3 \mathrm{~cm}$ (normal) & 102 & $25.8 \pm 20.2$ & $0.011 *$ \\
\hline C-BA $\leq 3 \mathrm{~cm}$ (impaired) & 183 & $21.4 \pm 19.1$ & \\
\hline \multicolumn{4}{|c|}{ Tetracaine used in the previous year } \\
\hline Yes & 242 & $19.4 \pm 18.1$ & $<0.00 I^{*}$ \\
\hline No & 137 & $24.8 \pm 11.3$ & \\
\hline \multicolumn{4}{|l|}{ History of ocular surgery } \\
\hline Yes & 143 & $19.1 \pm 18.0$ & $0.008^{*}$ \\
\hline No & 277 & $22.7 \pm 20.0$ & \\
\hline \multicolumn{4}{|l|}{ Dry eye disease } \\
\hline Yes & 137 & $21.0 \pm 18.5$ & 0.124 \\
\hline No & 287 & $22.6 \pm 19.7$ & \\
\hline \multicolumn{4}{|l|}{ Glaucoma } \\
\hline Yes & 49 & $21.0 \pm 19.8$ & 0.751 \\
\hline No & 375 & $21.6 \pm 19.4$ & \\
\hline \multicolumn{4}{|l|}{ Diabetic retinopathy } \\
\hline Yes & 82 & $17.3 \pm 17.1$ & 0.163 \\
\hline No & 342 & $20.9 \pm 19.2$ & \\
\hline
\end{tabular}

Note: $* P<0.05$

Abbreviations: C-BA, Cochet-Bonnet esthesiometer; VAS, visual analog scale. 
Table 3 Comparison of burning sensation assessed by VAS score between cold tetracaine and room temperature tetracaine in different subgroups (paired $t$-test, $\alpha=0.05$ )

\begin{tabular}{|c|c|c|c|c|}
\hline \multirow[t]{2}{*}{ Demographic data } & \multicolumn{3}{|c|}{ Burning sensation VAS score (mm) } & \multirow[t]{2}{*}{$P$-value } \\
\hline & $\mathbf{n}$ & $\begin{array}{l}\text { Cold tetracaine } \\
(\text { mean } \pm \text { SD) }\end{array}$ & $\begin{array}{l}\text { Room temperature } \\
\text { tetracaine (mean } \pm \text { SD) }\end{array}$ & \\
\hline \multicolumn{5}{|l|}{ Age, years } \\
\hline$\leq 40$ & 49 & $23.5 \pm 19.3$ & $35.7 \pm 24.3$ & $<0.001$ \\
\hline$>40$ & 375 & $20.1 \pm|8.7|$ & $20.9 \pm 18.7$ & 0.415 \\
\hline \multicolumn{5}{|l|}{ Gender } \\
\hline Male & 205 & $20.2 \pm 18.0$ & $20.8 \pm 19.4$ & 0.695 \\
\hline Female & 219 & $20.8 \pm 19.6$ & $24.5 \pm 20.5$ & 0.007 \\
\hline \multicolumn{5}{|l|}{ Corneal sensation, $\mathrm{cm}$} \\
\hline$>3$ & 102 & $23.8 \pm 19.1$ & $28.1 \pm 21.4$ & 0.009 \\
\hline$\leq 3$ & 183 & $20.7 \pm 18.5$ & $21.8 \pm 19.2$ & 0.57 \\
\hline \multicolumn{5}{|c|}{ Tetracaine used in the previous year } \\
\hline First-time user & 137 & $21.9 \pm 20.7$ & $27.9 \pm 21.7$ & 0.001 \\
\hline More than one time user & 242 & $19.7 \pm 18.3$ & $19.2 \pm 17.9$ & 0.676 \\
\hline \multicolumn{5}{|l|}{ History of ocular surgery } \\
\hline No & 277 & $21.1 \pm 19.4$ & $24.4 \pm 20.6$ & 0.006 \\
\hline Yes & 143 & $19.1 \pm 17.5$ & $19.0 \pm 18.5$ & 0.949 \\
\hline Dry eye disease & 137 & $18.5 \pm 19.5$ & $22.7 \pm 20.9$ & 0.08 \\
\hline \multicolumn{5}{|l|}{ Diabetic retinopathy } \\
\hline No & 342 & $21.3 \pm 19.1$ & $23.9 \pm 20.6$ & 0.076 \\
\hline Yes & 82 & $17.2 \pm 17.1$ & $17.1 \pm 17.5$ & 0.973 \\
\hline
\end{tabular}

Abbreviation: VAS, visual analog scale.

$(\mathrm{C}-\mathrm{BA}>3 \mathrm{~cm})$ experienced more beneficial effect from cold tetracaine $(23.8 \pm 19.1$ vs $28.1 \pm 21.4 ; P=0.009)$ as shown in Table 3.

\section{Discussion}

Tetracaine is the most commonly used topical eye anesthesia due to its efficacy and safety. ${ }^{2,3}$ However, it has some adverse effects such as burning sensation upon instillation and ocular irritation. ${ }^{4}$ Due to this adverse effect, it may reduce patient cooperation after tetracaine is instilled. There have been attempts to find ways to decrease these limitations.

Li et al ${ }^{12}$ conducted a crossover study in a 22 healthy subjects and compared ocular pain upon instillation between cold $\left(4^{\circ} \mathrm{C}\right)$ and room temperature $\left(19^{\circ} \mathrm{C}-21^{\circ} \mathrm{C}\right)$ tetracaine. The volunteers received one temperature in one eye and after at least 24 hours received alternate temperature in the same eye. VAS score was recorded right after tetracaine was instilled. They found that ocular pain was lessened when tetracaine was stored in cold temperature compared to room temperature. The limitation of this study is that VAS score was recorded on a different day, therefore making it difficult to recall. Furthermore, the number of subjects in the studied population was small.
In their study, Soltani et al ${ }^{11}$ recruited 60 patients, aged 50-70 years, undergoing phacoemulsification. This study compared ocular pain upon instillation of cold and room temperature tetracaine. Each subject was randomized to receive only cold or room temperature tetracaine. It was found that cooling tetracaine reduced the pain on instillation compared to room temperature solution. This study recruited the subjects who were undergoing phacoemulsification. This is more generalizable than the study of $\mathrm{Li}$ et al, ${ }^{12}$ who recruited healthy persons as their study subjects. However, as the effects of room temperature and cold tetracaine were assessed in two different populations of patients, there might be differences in baseline characteristics of both the groups, which lead to the possibility of selection bias and confounders, hence limiting the internal validity of the study.

Callear ${ }^{1}$ studied 60 subjects. The author randomized patients into three groups, with 20 patients in each, to receive amethocaine or oxybuprocaine or lignocaine eye drops. Each patient received warm temperature $\left(42^{\circ} \mathrm{C}\right)$ topical anesthetic in one eye and the same solution at room temperature $\left(22^{\circ} \mathrm{C}-25^{\circ} \mathrm{C}\right)$ in the other eye. The result showed that there was no significant difference in the discomfort caused by 
different temperatures (warm vs room temperature) in any of the three anesthetic drugs.

The study of Mansour et $\mathrm{al}^{8}$ compared the effects of warm $\left(20^{\circ} \mathrm{C}\right)$ and cold temperature $\left(4^{\circ} \mathrm{C}\right)$ on ocular discomfort of the dilating drops (tropicamide and phenylephrine) in 40 patients. Each patient received cold solutions in one eye and warm solutions in the other eye. The result showed that there was no difference in ocular discomfort between cold and warm dilating eye drops.

Based on the previous studies, the effect of temperature on burning sensation upon instillation of topical eye drops is still controversial. This led us to conduct the double-blinded, randomized controlled trial with a large sample size in order to answer this important research question.

The result of our study showed that cold temperature tetracaine caused less burning sensation than room temperature tetracaine upon instillation. This conformed to the findings of the studies of $\mathrm{Li}$ et $\mathrm{al}^{12}$ and Soltani et al. ${ }^{11}$

The mechanism of how cooling tetracaine reduces the burning sensation could be explained by many theories. Cold temperature could reduce the nerve conduction velocity ${ }^{14}$ and lead to pain reduction. Cold pack or icepack is used to reduce pain in the musculoskeletal system, ${ }^{15,16}$ and its onset of effect seems to be very rapid. Therefore, it is very likely that one of the main mechanisms by which cold temperature tetracaine alleviates burning sensation could be explained by the direct effect of temperature on nerve conduction. Through this mechanism, cold ophthalmic solutions, including tetracaine and artificial tears, have been found to be effective in pain reduction. ${ }^{11,17}$ Fujishima et $\mathrm{al}^{17}$ found that cooled artificial tears decreased corneal sensation and gave comfort to the patient. Vasoconstriction caused by cold temperature is another mechanism that plays an important role in pain reduction. Previous studies have shown that the cold ophthalmic solution induces vasoconstriction ${ }^{15,16,18}$ and could reduce the inflammatory cells and mediators. One study showed that cold pack applied after cataract surgery reduced inflammation. In the study, the authors evaluated inflammation using laser flare-cell meter. They found that there was a significant cell count reduction in inflammation on days 1, 3, 7 and 14 and a significant reduction in flare counts on days 1, 14 and 28 after surgery in the cooled eye. ${ }^{19}$

In our study, for room temperature tetracaine, mean VAS was $22.70 \pm 20 \mathrm{~mm}$, which was much less than that reported in other studies (mean VAS scores were $35.5 \pm 17.5^{11}$ and $49 \pm 22 \mathrm{~mm}^{12}$ ). The reduction of 2.7 from 22.7 is $\sim 10 \%$, which was in accordance with the other study, ${ }^{12}$ and we would expect the reduction to be greater in patients with inflamed eyes or in those who are more sensitive to tetracaine solution. In addition, we assessed patients' preference between cold and room temperature tetracaine and found that most of the patients preferred cold to room temperature tetracaine and some patients found no difference between the two solutions ( $45.5 \%$ vs $31.8 \%$ vs $22.7 \%$, respectively). Thus, we believe that the difference might have clinical significance, and cold solution could be beneficial in many patients who suffer from this common side effect of tetracaine. Moreover, different cultural backgrounds of different study populations may also play some role. Thai people are usually much more considerate. It is quite unusual for Thai patients to complain or express their feeling to their physicians. They tend to express less pain or discomfort than what they actually feel when asked by medical personnel. Nevertheless, the benefit of cold tetracaine was observed even in patients with low VAS score as in our study. We expect that the benefit of using cold tetracaine might even be more substantial if used in patients with higher VAS score.

In the subgroup analysis, we found that the patients who had no previous ocular surgery, the patients who had preserved corneal sensation $(\mathrm{C}-\mathrm{BA}>3 \mathrm{~cm})$ and the patients who used tetracaine for the first time in the previous year, had more VAS burning sensation score (sensitive subgroups). These sensitive subgroups of patients, who experienced more pain with tetracaine, were found to have greater benefit from using cold solution. This suggests that cold tetracaine is especially useful in those who are expected to experience more pain.

The strengths of our study are as follows. First, it is the largest double-blinded, randomized controlled trial to date. Second, the sample size was precalculated and was large enough for subgroup analysis. Third, we performed C-BA to evaluate corneal sensation, whereas in most of the other studies, the subjects were excluded by using the history of corneal neuropathy. Fourth, the sequence of instillation of tetracaine was also randomized. We found that the sequence had no impact on the patients' perspective of pain. Fifth, this is the first study that performed a subgroup analysis and provided extended knowledge to be applied to clinical practice.

The limitation of our study is that, we neither assessed the duration of discomfort nor the efficacy of anesthesia.

The results of this study lead to an important clinical implication. We recommend storing tetracaine in a refrigerator and using cold tetracaine to reduce burning sensation upon instillation in routine clinical practice, especially to sensitive groups of patients.

The effect of cold temperature that was found in this study should be further studied with broader groups of patients, 
such as patients who have inflamed eye, patients with corneal ulcer, patients with neuropathic pain or patients who have painful eye disease.

\section{Conclusion}

Cold ophthalmic tetracaine causes less burning sensation than room temperature solution. Its benefit is more in the subgroup of patients who experience greater burning sensation.

\section{Disclosure}

The authors report no conflicts of interest in this work.

\section{References}

1. Callear AB. The effect of temperature on the discomfort caused by topical local anaesthesia. $J R$ Soc Med. 1995;88(12):709p-711p.

2. Shafi T, Koay P. Randomised prospective masked study comparing patient comfort following the instillation of topical proxymetacaine and amethocaine. Br J Ophthalmol. 1998;82(11):1285-1287.

3. Bartfield JM, Holmes TJ, Raccio-Robak N. A comparison of proparacaine and tetracaine eye anesthetics. Acad Emerg Med. 1994;1(4):364-367.

4. Yau GL, Jackman CS, Hooper PL, Sheidow TG. Intravitreal injection anesthesia - comparison of different topical agents: a prospective randomized controlled trial. Am J Ophthalmol. 2011;151(2):333-337.e2.

5. Poulsen TD, Freund KG, Arendrup K, Nyhuus P, Pedersen OD. Polyurethane film (Opsite) vs. impregnated gauze (Jelonet) in the treatment of outpatient burns: a prospective, randomized study. Burns. 1991;17(1): 59-61.

6. Goel S, Chang B, Bhan K, El-Hindy N, Kolli S. "Cryoanalgesic preparation" before local anaesthetic injection for lid surgery. Orbit. 2006;25(2): $107-110$.

7. Leff DR, Nortley M, Dang V, Bhutiani RP. The effect of local cooling on pain perception during infiltration of local anaesthetic agents, a prospective randomised controlled trial. Anaesthesia. 2007;62(7):677-682.
8. Mansour AM. Tolerance to topical preparations: cold or warm? Ann Ophthalmol. 1991;23(1):21-22.

9. Weaver CS, Rusyniak DE, Brizendine EJ, et al. A prospective, randomized, double-blind comparison of buffered versus plain tetracaine in reducing the pain of topical ophthalmic anesthesia. Ann Emerg Med. 2003;41(6):827-831.

10. Young AL, Leung GY, Cheng LL, Lau TT, Lam PT, Lam DS. Randomised controlled trial on the effectiveness of lidocaine gel vs tetracaine drops as the sole topical anaesthetic agent for primary pterygium surgery. Eye (Lond). 2009;23(7):1518-1523.

11. Soltani AE, Ganji M, Goodarzi M, Moghimi S. Cooling tetracaine to reduce pain of instillation before surgery. Eye (Lond). 2009;23(6):1470.

12. Li SF, Flannigan K, Lupow J. Discomfort and tetracaine. Ophthalmology. 2006;113(1):164.

13. Hu Youwei J, Chang B. Effect of cooling proparacaine $0.5 \%$ eye drops on patient's comfort during instillation. Eye (Lond). 2015;29(8): 1112-1113.

14. Algafly AA, George KP. The effect of cryotherapy on nerve conduction velocity, pain threshold and pain tolerance. Br J Sports Med. 2007; 41(6):365-369.

15. Bleakley C, McDonough S, MacAuley D. The use of ice in the treatment of acute soft-tissue injury: a systematic review of randomized controlled trials. Am J Sports Med. 2004;32(1):251-261.

16. Meeusen R, Lievens P. The use of cryotherapy in sports injuries. Sports Med. 1986;3(6):398-414.

17. Fujishima H, Yagi Y, Shimazaki J, Tsubota K. Effects of artificial tear temperature on corneal sensation and subjective comfort. Cornea. 1997; 16(6):650-634.

18. Bleakley CM, McDonough SM, MacAuley DC, Bjordal J. Cryotherapy for acute ankle sprains: a randomised controlled study of two different icing protocols. Br J Sports Med. 2006;40(8):700-705.

19. Fujishima H, Yagi Y, Toda I, Shimazaki J, Tsubota K. Increased comfort and decreased inflammation of the eye by cooling after cataract surgery. Am J Ophthalmol. 1995;119(3):301-306.
Clinical Ophthalmology

\section{Publish your work in this journal}

Clinical Ophthalmology is an international, peer-reviewed journal covering all subspecialties within ophthalmology. Key topics include: Optometry; Visual science; Pharmacology and drug therapy in eye diseases; Basic Sciences; Primary and Secondary eye care; Patient Safety and Quality of Care Improvements. This journal is indexed on Submit your manuscript here: http://www.dovepress.com/clinical-ophthalmology-journal

\section{Dovepress}

PubMed Central and CAS, and is the official journal of The Society of Clinical Ophthalmology (SCO). The manuscript management system is completely online and includes a very quick and fair peer-review system, which is all easy to use. Visit http://www.dovepress.com/ testimonials.php to read real quotes from published authors. 